\title{
Analysis of the single-phase photovoltaic grid-connected cascaded H-bridge multilevel inverters
}

\author{
Hassan Salman Hamad* \\ Middle Technical University, Baghdad, Technical Instructors Training Institute, Iraq
}

\section{(C2017 ACCENTS}

\begin{abstract}
The technology of multilevel inverters has appeared as a significant alternate in the high power energy at medium voltage region. The cascaded $\mathrm{H}$-bridge $(\mathrm{CHB})$ rectifier configuration is appropriate for random numbers of series bridges with various levels of voltages and powers. This paper offer a single phase three levels and nine levels photovoltaic (PV) inverter topology that can be applied for PV systems of grid connecting to a normal pulsed width modulating (PWM) controlled system. The simulation of MATLAB based on Simulink have been presented for total harmonic distortions (THD) for output signals and the output phase of voltage and current in addition to PWM signal for IGBT. The designed system is confirmed through simulation that THD may be reduced within increased level numbers and this certifies a suggested controlling approach.
\end{abstract}

\section{Keywords}

Cascaded H-bridge, Multilevel inverter, Photovoltaic, THD.

\section{Introduction}

For the time being, the renewable energy (RE) considers as a main motivation of an energy division, mainly due to its friendly of environments, clean, in addition to safe sources of energy [1]. The renewable energy's desire possesses significantly improvement during last decades because there are many effects deals with a shortage of like a greenhouse and fossil fuels. Amongst many sources forms of renewable energies, the solar energies as well as wind energies consider most widespread and challenging owing to technical developments in power-electronics. The power generation of photovoltaic (PV) can be supposed the best favourable technologies which may be used in power electronics systems and countryside electrification [2]. The sources of Photovoltaic (PV) have been utilized nowadays in several applications result from the advantages like a pollution and maintenance are free. The demand of solar electrical energy have developed constantly over two decades by $20 \%$ to $25 \%$ per annum, that's essentially due to costs as well as prices reducing [3]. PV generators are supplying only DC power, so that an inverter is mandatory for connecting loads to the generator [4].

*Author for correspondence 108
A basic advantage for better inverter's power deals with it's capable of providing power with highquality, clean and has fixed amplitude AC voltage and frequency, nevertheless to the connected load. Moreover, a capability of power inverter to have quickly recovering from any transient that affected by peripheral disturbances in spite of quality initiating of power problems [5].

The improvement of power electronics and an evolving of new topologies of the converters of multilevel, there is a possibility for working with voltages less than specific power of devices [6]. The multilevel converters (MLI) accomplish switching of high-voltage with sequences of voltage stages. MLIs can be essentially utilized in applications of medium systems or furthermore high power systems, like a compensation of static responsive power and also drives of adjustable-speed [7]. With a restrictions of the presently existing technologies of power semiconductor in these applications, a multilevel model is typically an exclusive alternative due to its cantered on switching low-frequencies with voltage supplying and current involvement among the semiconductor power [8]. These MLIs may be essentially divided to cascaded H-bridge and diode clamp, in addition to flying-capacitor structures. Amongst all topology, a cascaded $\mathrm{H}$ bridge appears mainly attractive in applications of higher voltages, due to its structure has particularly modular, it has 
got a soft physical arrangement, with a few numbers of components if it compared with another topology [9].

Instead, with a low-power schemes (less than 10 $\mathrm{kW}$ ), MLIs can be competed with a high-frequency converters which uses pulse width-modulation for high efficiency applications are of a main importance. Furthermore, low costs for both switching power besides advanced technology of semiconductors, along with a recent demanding on great performances inverters preferred with renewable energy schemes, could prolonged MLIs implementation [10,11].

Multilevel inverters consist of group of power semiconductors as array and sources of capacitor voltages, the output that a voltage generated with a step waveform. The switch's commutation allows for the capacitor voltages addition, which accomplish output high voltage, while a withstanding of power semiconductors can only reducing voltages. Inverters with single phase leg schematic diagram can be shown in Figure 1 with various level numbers, which a behaviour of the semiconductor power can be denoted with an perfect switch have several positions. A output voltage of inverter's two-level can be generated within two levels and inverter's threelevel can be generated three voltages all respected to the capacitor's negative terminal and so $\mathrm{n}$ levels[12].

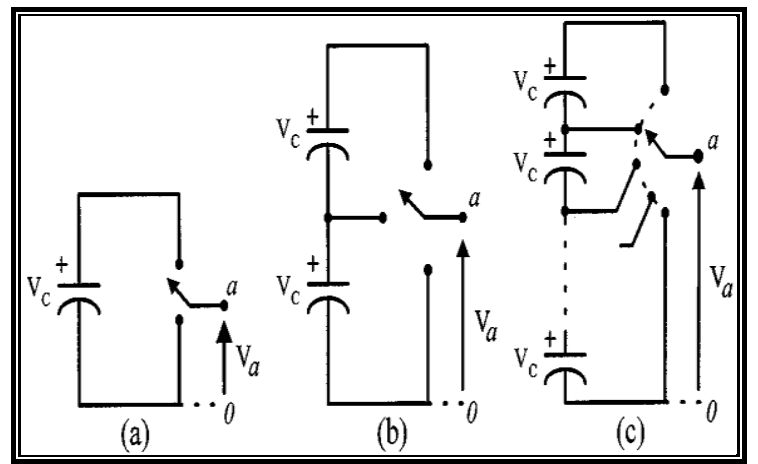

Figure 1 An inverter single phase leg (a) 2 levels (b) 3 levels (c) n levels.

Under these schemes of new generation of electricity, it is practicable for implementing interfaces through the capability to operate first, in grid connecting approach with inserting energy generated by sources of renewable for the grid, second as well as in islanding mode providing a locally loads out connection of grid. These interfaces which can be well-known as micro grids are usually collected from low voltage systems and may be a medium, and fed from sources of distributing generations like micro turbines, or PV systems simultaneously with storage energies devices in addition to the loads [13].

\section{MLI topologies}

A power converters interface which from a dc source toward load or/and toward grid usually contains many stages converter : first a dc- to- dc converters and second a dc- to- ac converters. A motivating alternate explanation may be with a using of a converter of one stage wherever a dc- to- dc converter can avoids, also so as to confirm the required voltage, arrays of PVs maybe a series panels of PVs or maybe an assembly of PV panels with parallel strings. For the two-stage converter at a classical solution, the dc-dc converter needs further devices for creating a big amounts of conduction losses, inactive transient responses and very expensive while single stage converter have an advantages of: high efficiency, cheap and easy for implementation. On the other side, the disadvantages are based on actuality that, the connection of PV panels are in series so that if any one or more shading arises for PV panels, an efficiency is reduced of the complete system [14].

Another topology of converters can be introduced which created on connection string of inverters (single phase) in addition to discrete DC voltage [12]. Figure 2 explains a power scheme of single phase leg for the nine levels inverter which has with each phase four cells. The voltage of resulted phase can be synthesized through the adding of the generating voltages by the various cells. A full-bridge inverter at any single-phase can be generated three output values of voltages: $+V_{d c}, \mathrm{O}$, and $-V_{d c}$. This has become possible via connected capacitors in sequences along with ac side by four switches of power. A resulted voltage will be fluctuated by $-4 V_{d c}$ steps to $+4 V_{d c}$ steps for the nine levels; therefore the stairs waveforms can be approximately sinusoidal, in spite of no filtering.

Alternative form of Cascaded ML Inverter utilizing standard 2-level inverters of 3-phases which had been proposed by Cengelci [15], they used output transformer for adding the various voltages to his circuit, as explained in Figure 3. The ML Inverters output of a three sections must be in synchronization with a $120^{\circ}$ separation between all phases for the output voltages of ML Inverters which can be added. That's main, to obtain an output voltages of three level between a, b terminals, a voltage can be 
produced by $\boldsymbol{V}_{\boldsymbol{a} b}=\left(\boldsymbol{V}_{a 1}-\boldsymbol{V}_{\boldsymbol{b} 1}\right)+\left(\boldsymbol{V}_{\boldsymbol{b} 1}-\boldsymbol{V}_{\boldsymbol{a} 2}\right)$ $+\left(V_{a 2}-V_{b 2}\right)$. While the phase between $a_{2}$ and $b_{1}$ can be supplied with $a_{3}$ and $b_{3}$ across the separated transformer. For a synchronized three inverters, the $\left(\boldsymbol{V}_{a 1}-\boldsymbol{V}_{b 1}\right),\left(\boldsymbol{V}_{b 1}-\boldsymbol{V}_{a 2}\right)$, and $\left(\boldsymbol{V}_{a 2}-\boldsymbol{V}_{\boldsymbol{b} 2}\right)$ voltages can be considered within phase, hence, the level output will be basically tripled.

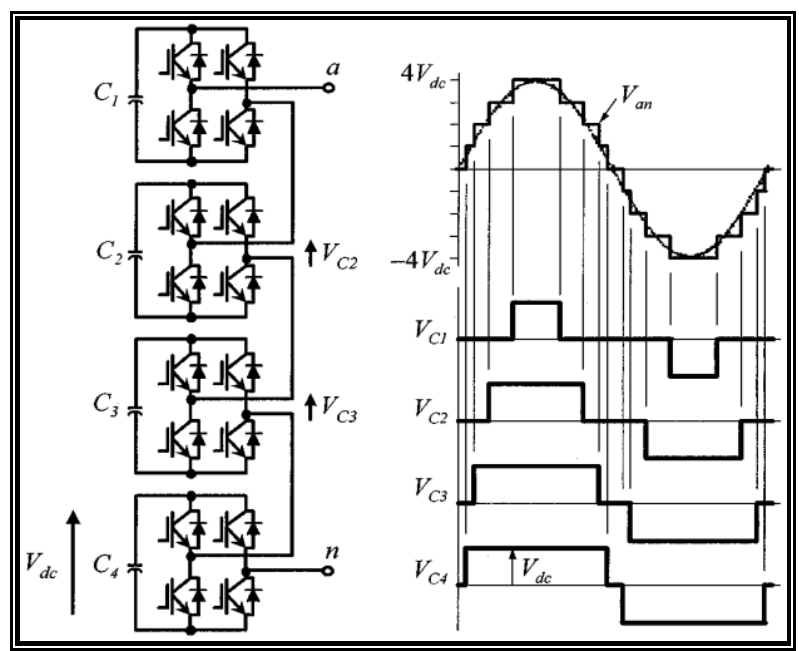

Figure 2 Topology of cascaded H-bridge inverter (CCT) and related waveforms

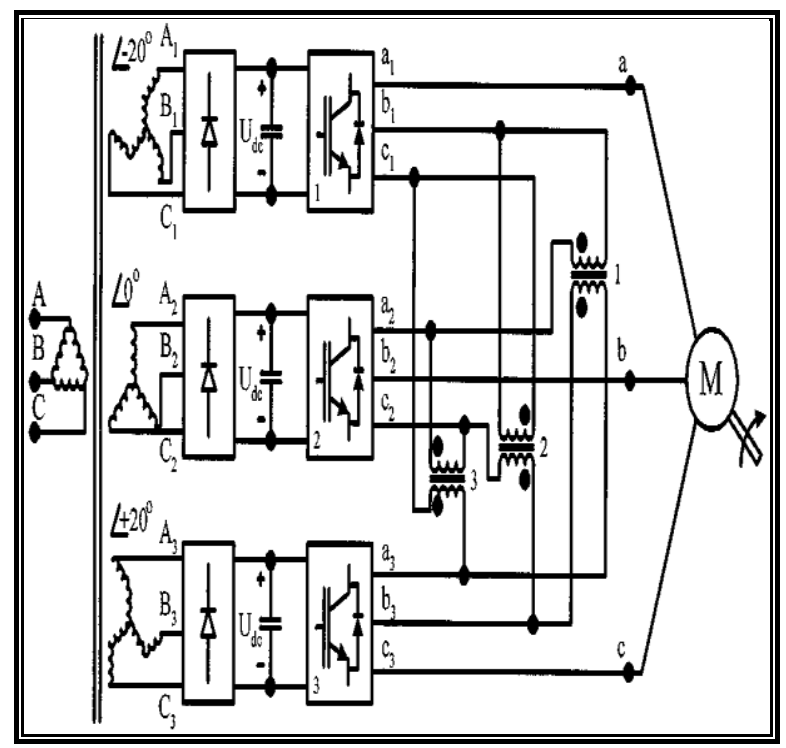

Figure 3 Three-phase cells of cascaded ML inverter

The simple topology discussed here is collected of many H-bridge converters connected in cascade form. Figure 4 demonstrates an inverter of two-cell.
A cascade form topology permits to be used a dc sources but have different values of voltage, so multilevel waveforms with achievement of high resolution and components number comparatively are very low [16]. Furthermore, dc sources may be added as well as subtracted for increasing the output level numbers.

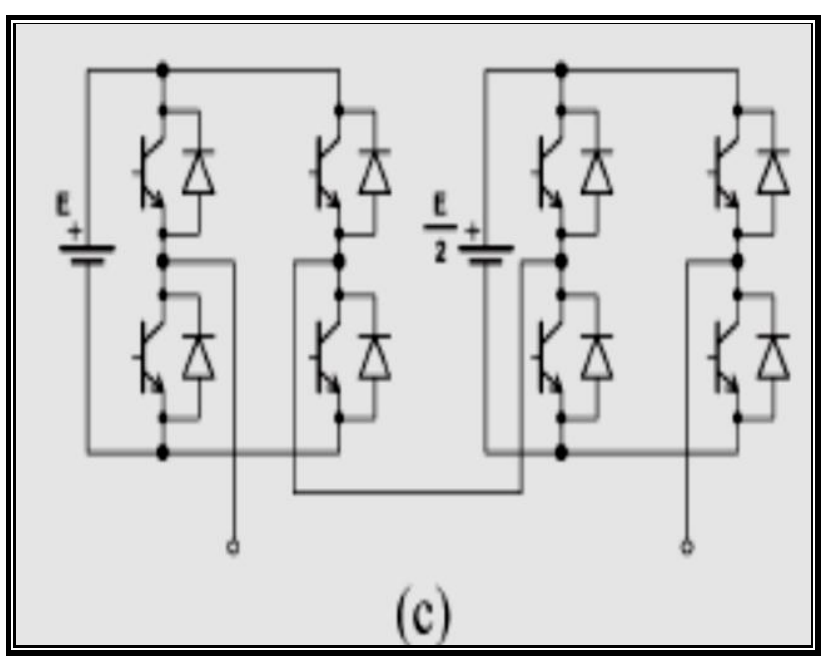

Figure 4 Cascaded H-bridge configurations

The arrangement of a rectifier cascaded $\mathrm{H}$ bridge (CHB) maybe presented as in Figure 5 with $\mathrm{n}$ series of Bridges, each one comprises 4 switches and antiparallel diode with single capacitor. Then terminal voltages $\mathrm{V}_{\mathrm{ab}}, \mathrm{V}_{\mathrm{bc}}, \mathrm{V}_{\mathrm{xn}}$ of the rectifier can be given by:

$V_{a n}=V_{a b}+V_{b c}+\cdots+V_{x n}$

Van is the total voltage rectifier ac terminals. Three levels of voltage can be generated at every ac side H-bridge: $\mathrm{V}_{\mathrm{C}}$, level $\mathrm{O}$, and $-\mathrm{V}_{\mathrm{C}}$. Obviously within $\mathrm{n}$ H-bridges, a generation of $(2 n+1)$ levels may be obtained on a rectifier ac terminal.

To generate $\mathrm{V}_{\mathrm{an}}=\mathrm{kV}_{\mathrm{C}}$ or $\mathrm{V}_{\mathrm{an}}=-\mathrm{kV}_{\mathrm{C}}$, a switching states of overall number with $\mathrm{m}$ and $\mathrm{k}$ stand for nonnegative integers while a function $C(n, k)$ can be considered combinations number of $n$ things occupied $\mathrm{k}$ in time can be achieved in (2) [9]:

$$
\sum_{m=0}^{m \leq \frac{n-k}{2}} C(n, k+m) \cdot C(n-m, m) \cdot 2^{n-(k+2 m)}, 0 \leq k \leq n
$$




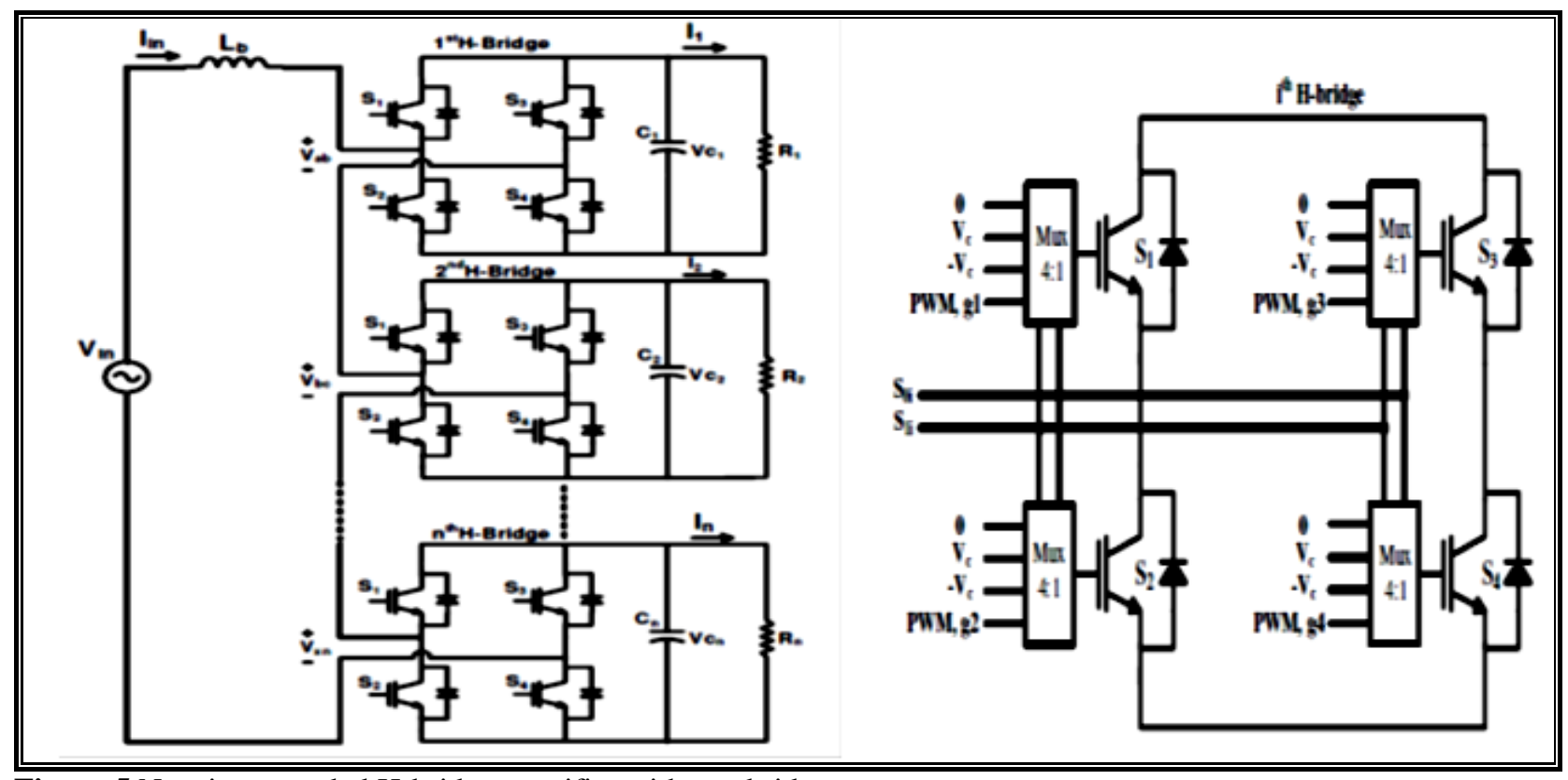

Figure $5 \mathrm{~N}$ series cascaded H-bridges rectifier with one bridge

For a power configuration explained in Figure 5 an inductance is exist concerning mains sides and rectifier side, $L_{b}$ to be utilized in formation of input currents. This configuration maybe worked as a double boost converter with $\mathrm{n}$ series $\mathrm{H}$-bridge instead of a single bridge. Further, it supports the flow of power in both directions utilizing four switches for any $\mathrm{H}$-bridge.

The exploited CHB's rectifier is really modular with an addition of being extended to different levels of voltages and power., the CHB configuration may be developed very easily, depend on a equal power losses, as well as used minimum components number with same condition in contrast with another kinds of multilevel converters, but there is only a drawback in this configuration represented by dc buses voltage balancing once it connected to different values of loads. This drawback can be solved by introducing a different control technique that is appropriate for random number of a series CHBs then power quality will be improved.

Finally, a single phase inverter with a topology of multi-levels photovoltaic (PV) is presented as shown in Figure 6 that can be used in grid-connecting PV structures based on a controlled pulsed width modulation (PWM) method. This inverter assumes a configuration of full-bridge connected to the auxiliary circuit and photovoltaic PV arrays can be connecting toward the inverter over a converter $\mathrm{dc}-$ dc boost.
This converter maybe utilized to improve the outputs of inverter $V_{\text {inv }}$ to become above $\sqrt{2}$ of $\mathrm{Vg}$ (grid's voltage) for confirming power flowing from the photovoltaic arrays to the grid [17]. The injecting filter current needs to be sinusoidal and has lower total harmonic distortions (THD) . For generating sinusoidal current, a pulse width modulation PWM is used, because Sinusoidal PWM considers the best and effective methods. It can be obtained by comparison of a high frequency carriers and a low frequency sinusoidal, a constant period of carriers and therefore switches have fixed switching frequency which are specified by the mixing of a carrier with a modulating signal [3].

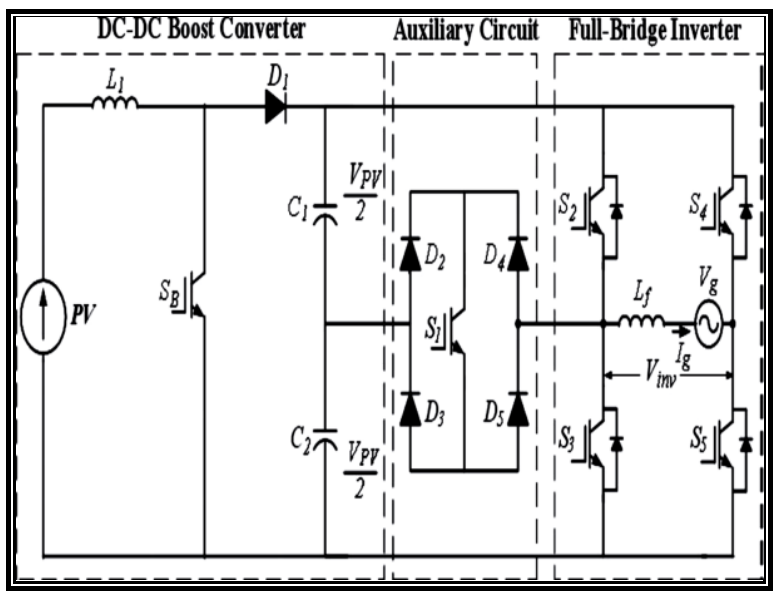

Figure 6 Multi-level single-phase inverter 
Hassan Salman Hamad.

\section{Simulation}

With a view to prove that the single phase inverter with multi-level photovoltaic can be essentially executed for a PV scheme, MATLAB/Simulink simulations were achieved. Simultaneous CHB multilevel inverters have been executed. The Simulating output voltages as well as output currents and THD analyses, in addition to the signals of generating switching will be established.
The symmetrical CHB multilevel inverters of three levels, or five, or seven, and nine will be generating by utilizing 4 , or 8 , or 12 , or 16 switches respectively. The conforming switching conditions and output voltage terminals of 3 and 9 level revealed multi-level inverter can be presented in Table 1 .

Table 1 Switching table of the 3 and 9 level conventional CHB-MLI

\begin{tabular}{|c|c|c|c|c|c|c|c|c|}
\hline \multirow[b]{2}{*}{ V(OUT) } & \multicolumn{4}{|c|}{3 Levels } & \multicolumn{4}{|c|}{9 Levels } \\
\hline & S1 & S2 & S3 & S4 & S13 & S14 & S15 & S16 \\
\hline $4 \mathrm{VP}$ & 1 & 0 & 0 & 1 & 1 & 0 & 0 & 1 \\
\hline $3 \mathrm{VP}$ & 1 & 0 & 0 & 1 & 1 & 1 & 0 & 0 \\
\hline $2 \mathrm{VP}$ & 1 & 0 & 0 & 1 & 1 & 1 & 0 & 0 \\
\hline VP & 1 & 0 & 0 & 1 & 1 & 1 & 0 & 0 \\
\hline $0 \mathrm{~V}$ & 1 & 1 & 0 & 0 & 1 & 1 & 0 & 0 \\
\hline$-V P$ & 0 & 1 & 1 & 0 & 0 & 0 & 1 & 1 \\
\hline$-2 \mathrm{VP}$ & 0 & 1 & 1 & 0 & 0 & 0 & 1 & 1 \\
\hline$-3 V P$ & 0 & 1 & 1 & 0 & 0 & 0 & 1 & 1 \\
\hline$-4 V P$ & 0 & 1 & 1 & 0 & 0 & 1 & 1 & 0 \\
\hline
\end{tabular}

3.1Three-levels inverter

CHB inverter of three-level diagram have four switching type IGBT seen in the Figure (7-a), these switching desires 4 pulses for inverting DC to AC. While from Figure $(7-b)$, an indication for total harmonic distortions THD for output signals, then output voltage with output Current could be seen at Figure (7-c), finally 4 PWM signals can be described at Figure $(7-d)$ for switching.

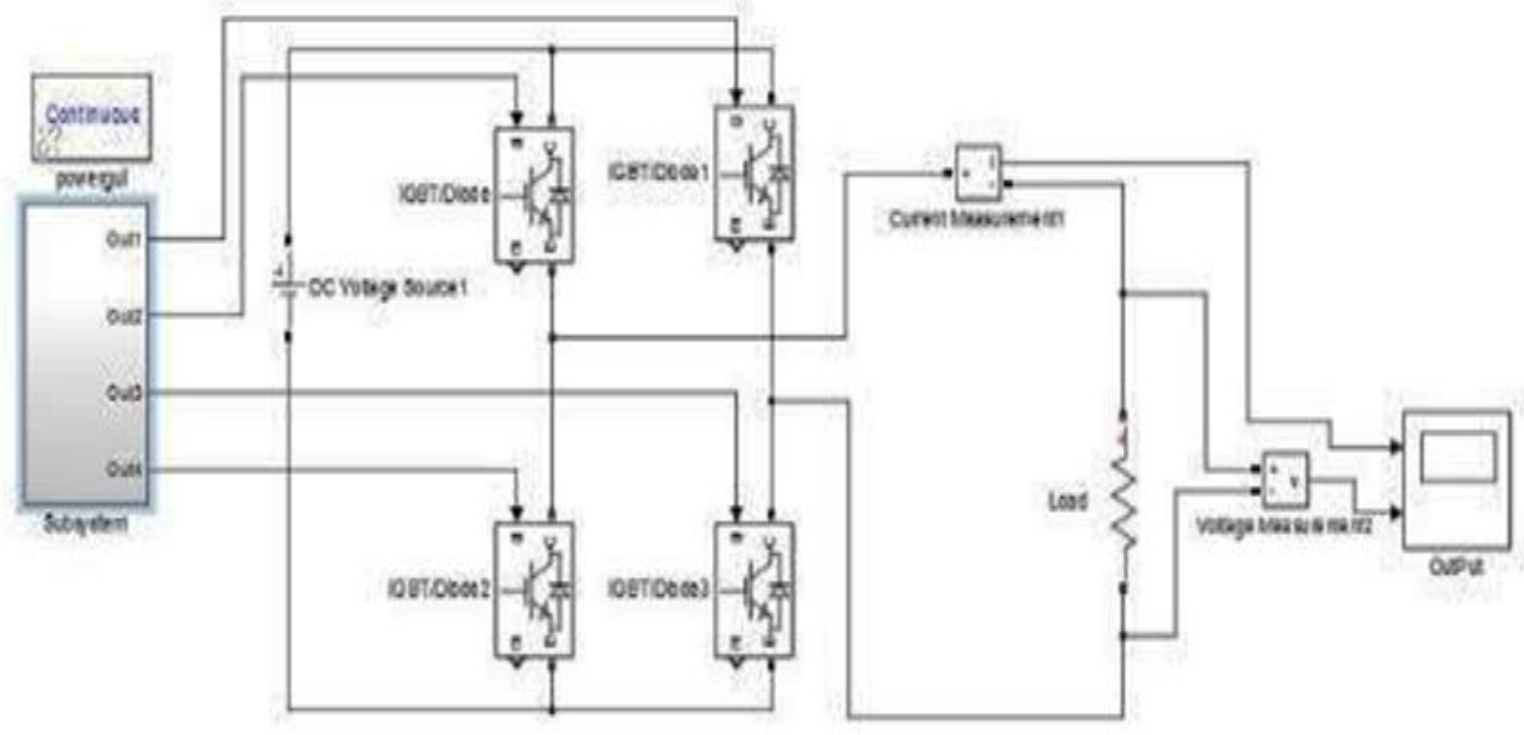

Figure (7- a) Circuit of 3- levels CHB inverter 


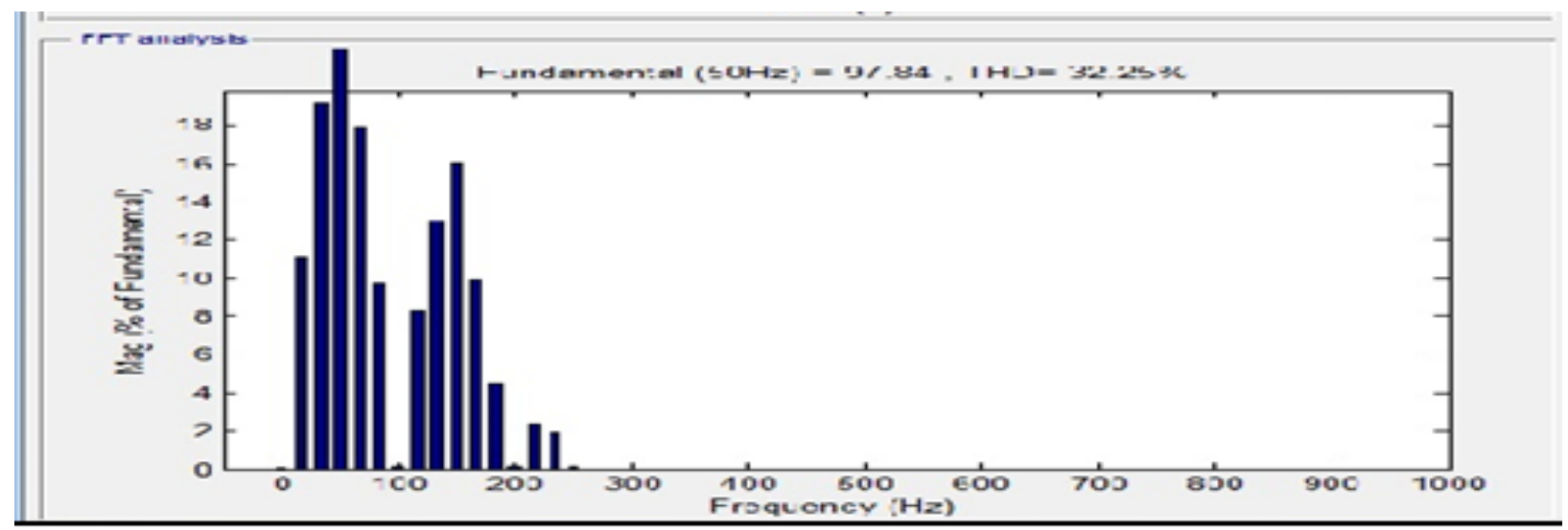

Figure (7-b) FFT of 3- level CH-Bridge MLI (THD)

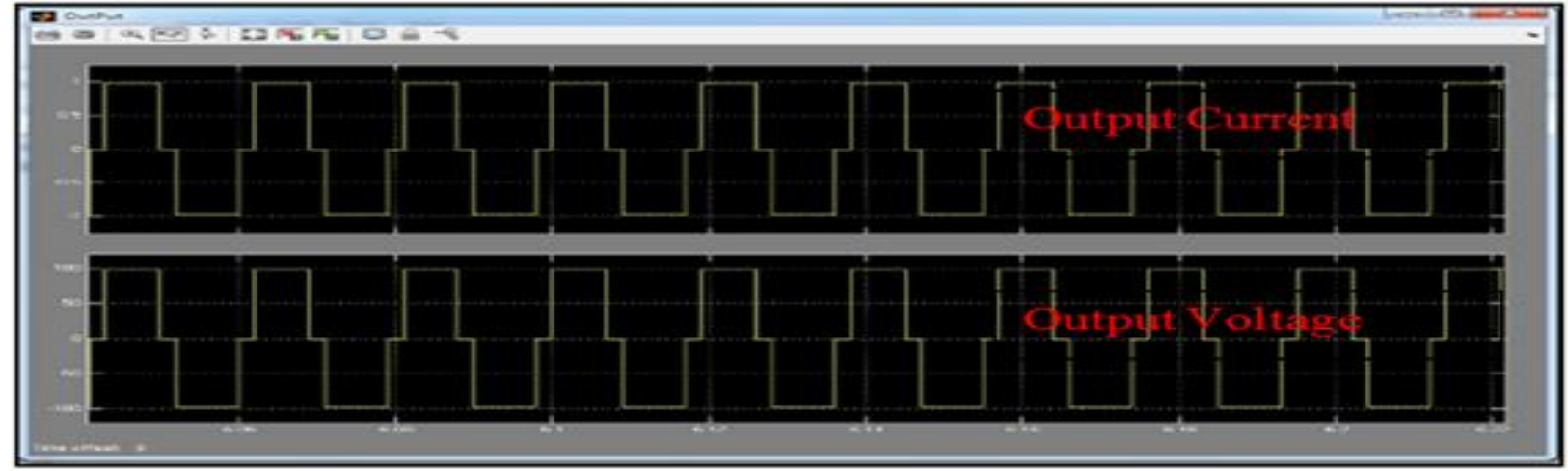

Figure (7-c) Out phase current voltage

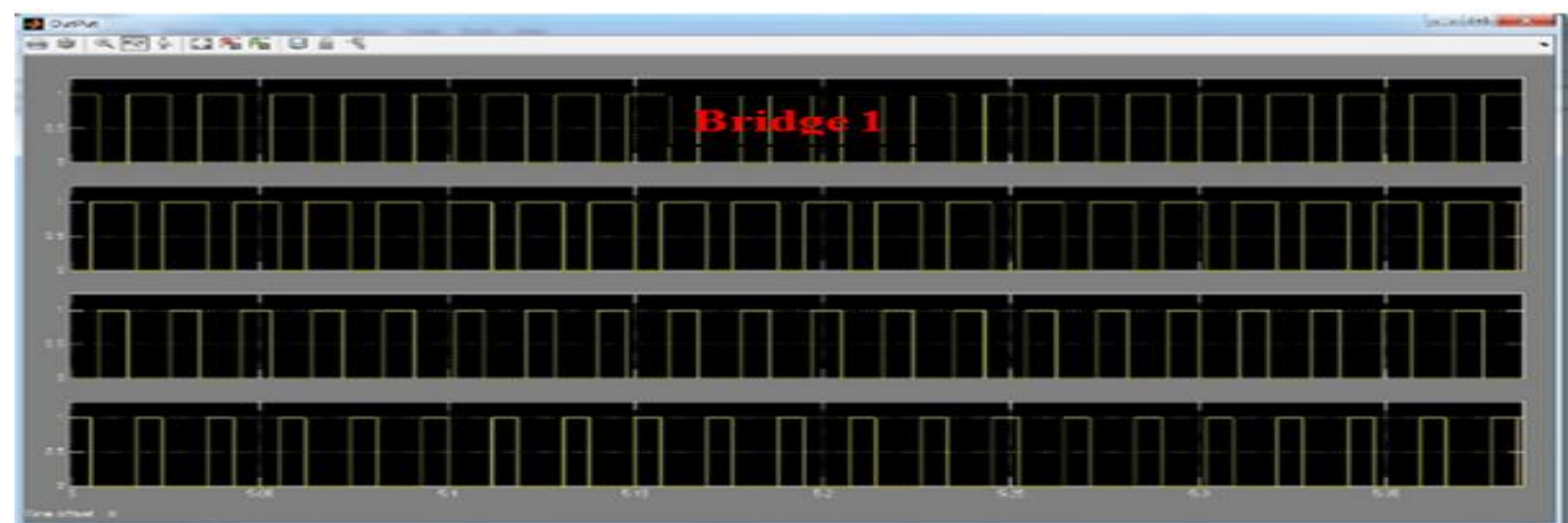

Figure (7-d) Generation of gating Pulses for PWM three level CHB using MATLAB

\section{Nine-level Inverter}

Nine -level cascade inverter circuit has 16 IGBT as shown in the Figure $(8-a)$. 16 IGBT necessity 16 pulses for inverting $\mathrm{DC}$ to $\mathrm{AC}$, whereas the total harmonic distortions THD for output signal can be shown in Figure $(8-b)$, the output Voltage and Current can be shown in Figure (8-c), and Figure (8d) explains the PWM signal for IGBT. 


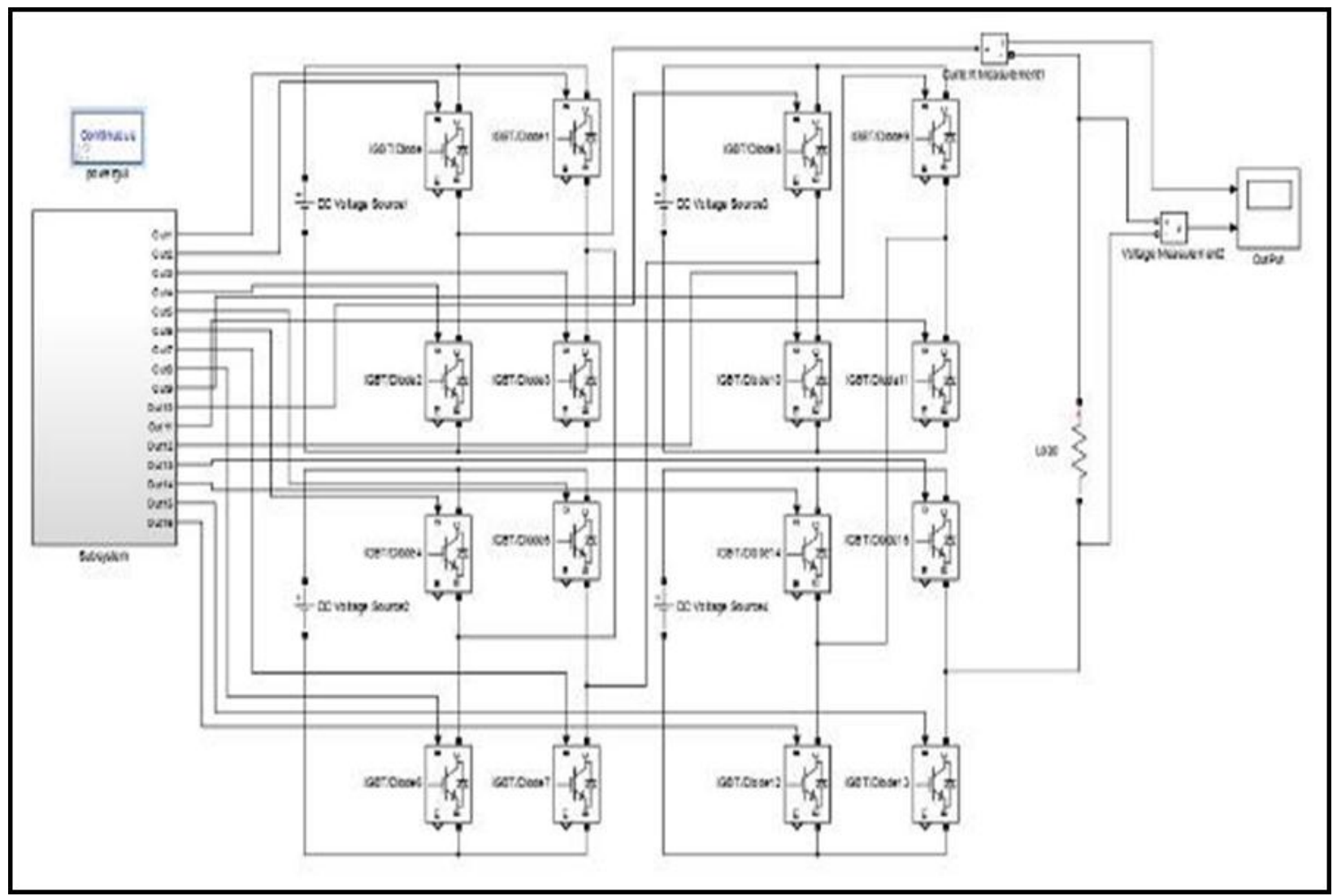

Figure (8-a) MATLAB/Simulink inverter circuit model of nine levels CHB

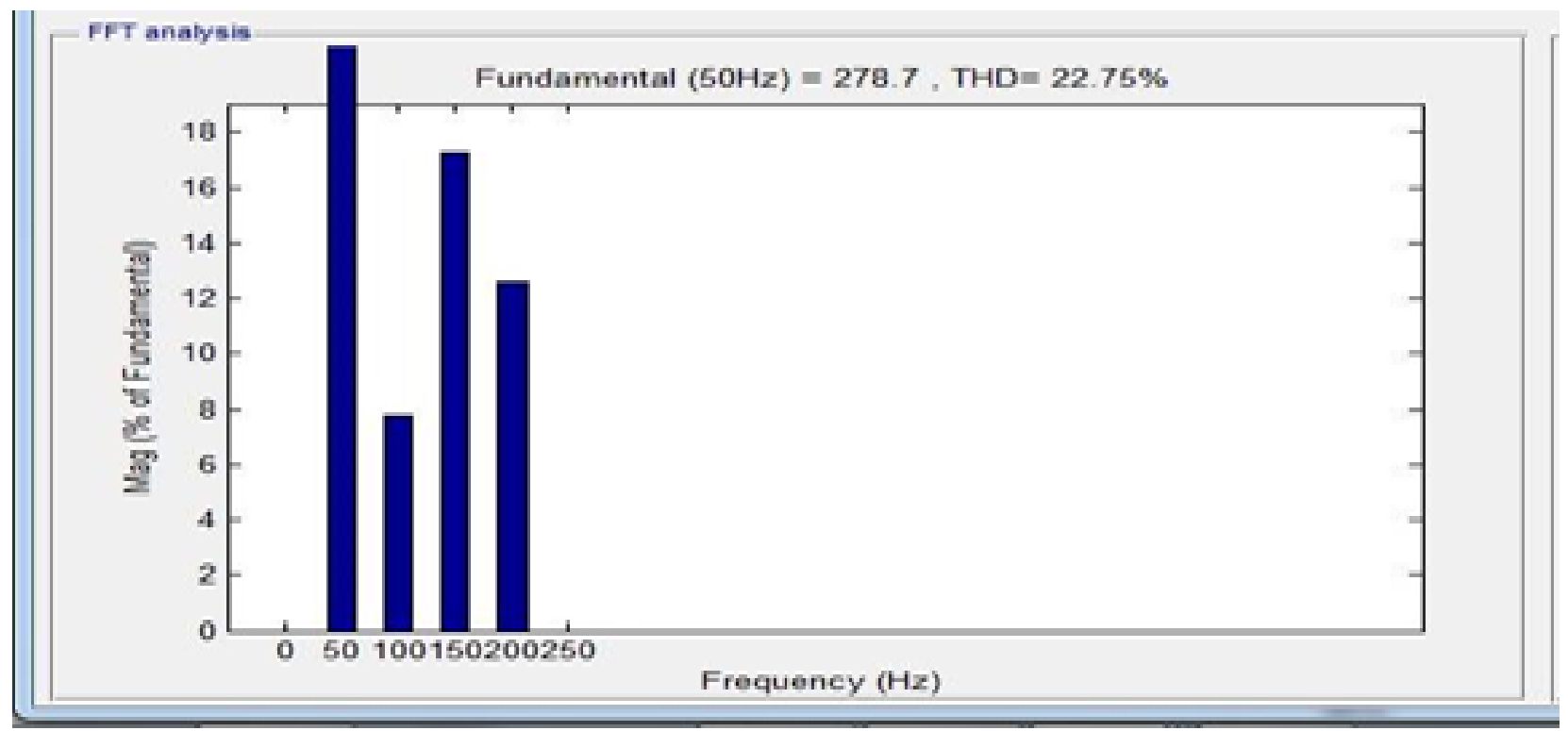

Figure (8-b) FFT analysis of cascaded H-Bridge MLI voltage 


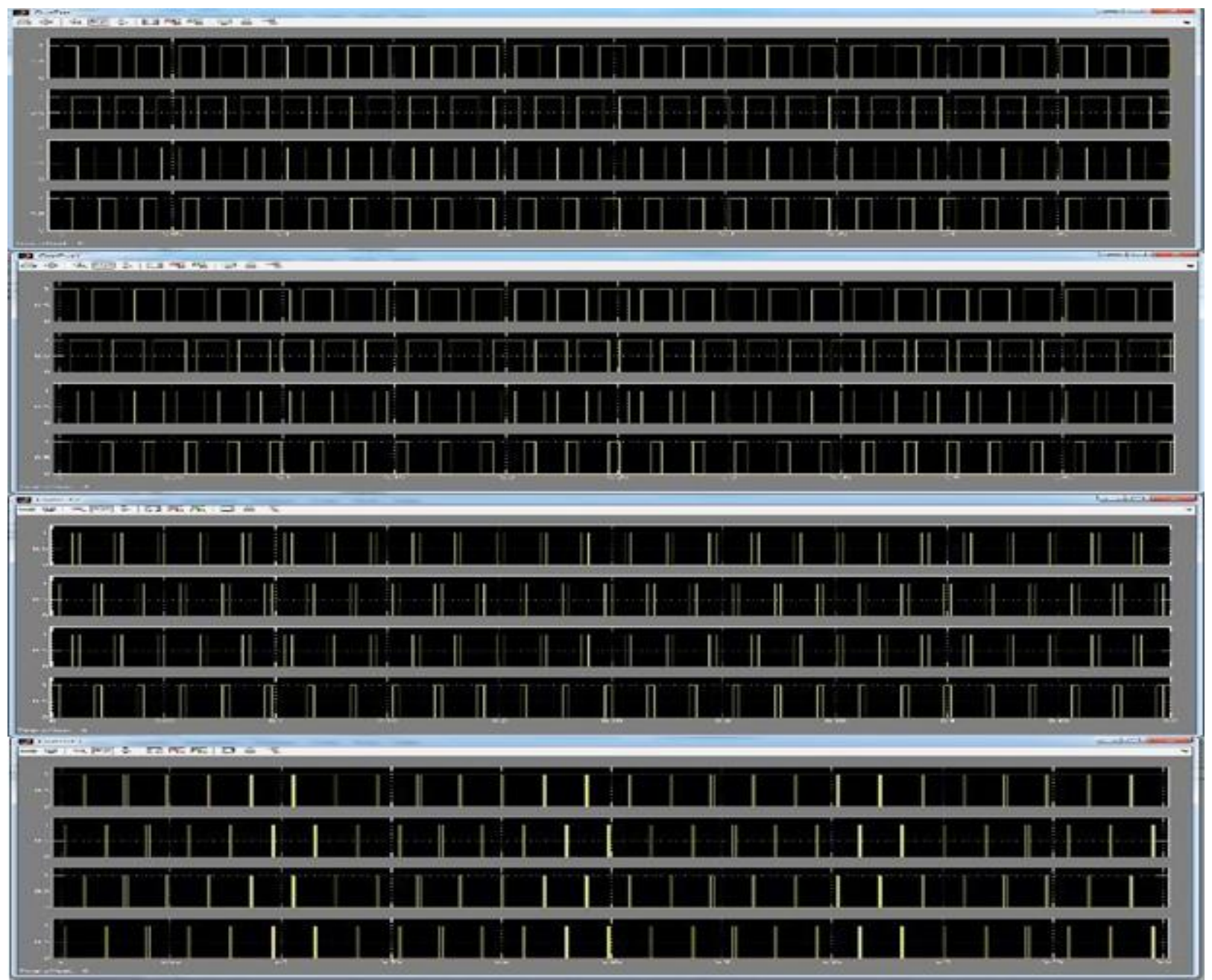

Figure (8-c) Output phase current and voltage

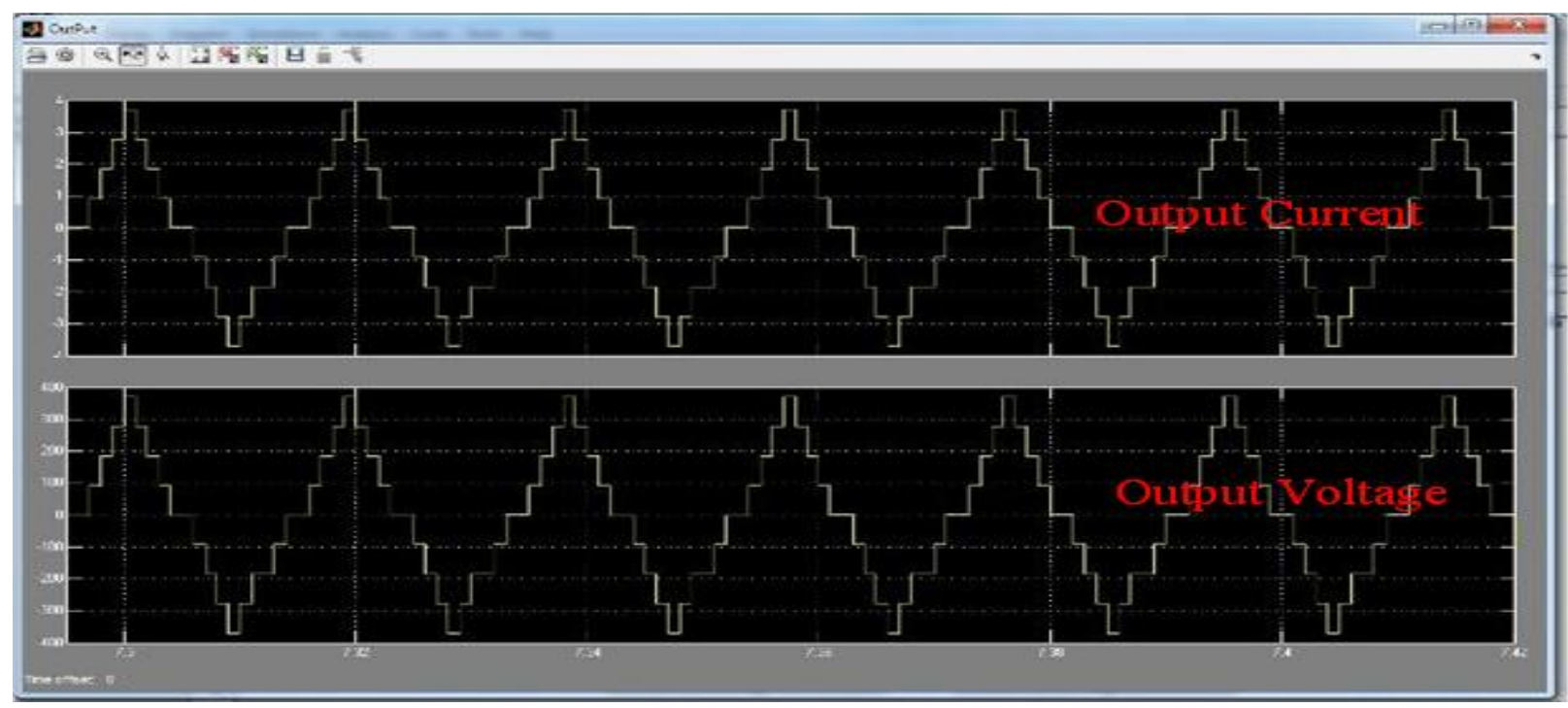

Figure (8-d) Output phase current and voltage 


\section{Conclusion}

The MATLAB based simulation on Simulink have been displayed for many various topologies of $\mathrm{CHB}$ Multilevel Inverter of three levels and nine levels inverters where a simple control strategy is applied for switching the IGBTs at appropriate conducting angles. The total harmonic distortion for each level had been calculated and compared. A comprehensive figure result of various topologies has been presented based on the number of power devices used. From the different levels of simulation it is clear that THD can be decreased by increasing number of levels which validates the proposed control strategy.

\section{Acknowledgment}

None.

\section{Conflicts of interest}

The author has no conflicts of interest to declare.

\section{References}

[1] Carrasco JM, Franquelo LG, Bialasiewicz JT, Galván E, PortilloGuisado RC, Prats MM, et al. Powerelectronic systems for the grid integration of renewable energy sources: A survey. IEEE Transactions on Industrial Electronics. 2006; 53(4):1002-16.

[2] Agelidis VG, Baker DM, Lawrance WB, Nayar CV. A multilevel PWM inverter topology for photovoltaic applications. In proceedings of the international symposium on industrial electronics 1997 (pp. 58994). IEEE.

[3] Selvaraj J, Rahim NA. Multilevel inverter for gridconnected PV system employing digital PI controller. IEEE Transactions on Industrial Electronics. 2009; 56(1):149-58

[4] Blaabjerg F, Chen Z, Kjaer SB. Power electronics as efficient interface in dispersed power generation systems. IEEE Transactions on Power Electronics. 2004; 19(5):1184-94.

[5] Mutlag AH, Mohamed A, Shareef H. A natureinspired optimization-based optimum fuzzy logic photovoltaic inverter controller utilizing an eZdsp F28335 board. Energies. 2016; 9(3):120.

[6] Cheng Y, Qian C, Crow ML, Pekarek S, Atcitty S. A comparison of diode-clamped and cascaded multilevel converters for a STATCOM with energy storage. IEEE Transactions on Industrial Electronics. 2006; 53(5):1512-21.
[7] Perantzakis GS, Xepapas FH, Manias SN. A novel four-level voltage source inverter-Influence of switching strategies on the distribution of power losses. IEEE Transactions on Power Electronics. 2007; 22(1):149-59.

[8] Daher S, Schmid J, Antunes FL. Multilevel inverter topologies for stand-alone PV systems. IEEE Transactions on Industrial Electronics. 2008; 55(7):2703-12.

[9] Iman-Eini H, Schanen JL, Farhangi S, Wang S. Design of cascaded H-bridge rectifier for medium voltage applications. In power electronics specialists conference 2007 (pp. 653-8). IEEE.

[10] Calais M, Agelidis VG, Meinhardt M. Multilevel converters for single-phase grid connected photovoltaic systems: an overview. Solar Energy. 1999; 66(5):325-35.

[11] Martins GM, Pomilio JA, Buso S, Spiazzi G. Threephase low-frequency commutation inverter for renewable energy systems. IEEE Transactions on Industrial Electronics. 2006; 53(5):1522-8.

[12] Rodriguez J, Lai JS, Peng FZ. Multilevel inverters: a survey of topologies, controls, and applications. IEEE Transactions on Industrial Electronics. 2002; 49(4):724-38.

[13] Ortega R, Figueres E, Garcerá G, Trujillo CL, Velasco D. Control techniques for reduction of the total harmonic distortion in voltage applied to a singlephase inverter with nonlinear loads. Renewable and Sustainable Energy Reviews. 2012; 16(3):1754-61.

[14] Ciobotaru M, Teodorescu R, Blaabjerg F. Control of single-stage single-phase PV inverter. EPE Journal. 2006; 16(3):20-6.

[15] Cengelci E, Sulistijo SU, Woo BO, Enjeti P, Teoderescu R, Blaabjerg F. A new medium-voltage PWM inverter topology for adjustable-speed drives. IEEE Transactions on Industry Applications. 1999; 35(3):628-37.

[16] Song BM, Kim J, Lai JS, Seong KC, Kim HJ, Park SS. A multilevel soft-switching inverter with inductor coupling. IEEE Transactions on Industry Applications. 2001; 37(2):628-36.

[17] Lee SJ, Bae HS, Cho BH. Modeling and control of the single-phase photovoltaic grid-connected cascaded $\mathrm{H}$ bridge multilevel inverter. In energy conversion congress and exposition 2009 (pp. 43-47). IEEE. 